\title{
Ketone Body Measurement
}

National Cancer Institute

\section{Source}

National Cancer Institute. Ketone Body Measurement. NCI Thesaurus. Code C111239.

The determination of the amount of ketone bodies (acetone, acetoacetic acid, betahydroxybutyric acid, beta-ketopentanoate and beta-hydroxypentanoate) present in a sample. 